\title{
Examination of the causes of early pregnancy-associated thrombocytopenia in mice
}

\author{
C. O’Neill* \\ Department of Veterinary Physiology, University of Sydney New South Wales 2006, Australia
}

\begin{abstract}
Summary. In mice, neither the bleeding time nor the clotting time of whole blood was different on Day 2 of pregnancy compared with pseudopregnancy. Standardization of the platelet concentration to $10^{6} / \mu \mathrm{l}$ plasma resulted in a significant reduction in the clotting time of plasma from pregnant animals. This reduction was not due to an increase in the intrinsic or extrinsic pathways of the coagulation cascade but to enhanced platelet factor III activity, indicating increased platelet activation and consumption. Increased activation was not due to immunological recognition of the embryo because thrombocytopenia occurred after syngeneic and allogeneic matings of inbred strains of mice and also after parthenogenetic activation of ova in situ. Injection of embryo culture medium into splenectomized mice induced a significant dosedependent thrombocytopenia. It occurred within $10 \mathrm{~min}$ after injection and persisted for up to $2 \mathrm{~h}$. There was no reduction in platelet count when animals were injected with culture media in which unfertilized ova had been incubated. Early pregnancyassociated thrombocytopenia was caused by the production of platelet-activating factors by the fertilized eggs. The induction of thrombocytopenia by embryo culture media displayed a dose-response curve that was parallel to that of the plateletactivating factor, 1-0-alkyl-2-acetyl-sn-glycero(3)phosphocholine.
\end{abstract}

\section{Introduction}

Thrombocytopenia has been shown to be an initial maternal response to conception (O'Neill, 1985). A significant reduction in blood platelet numbers occurred within $6 \mathrm{~h}$ of fertilization and was maintained for the first week of pregnancy. This response was dependent upon the presence of fertilized eggs, and the extent of thrombocytopenia was directly correlated with the number of zygotes in the reproductive tract (O'Neill, 1985). This paper examines whether thrombocytopenia in early pregnancy in mice was: (1) due to intravascular coagulation in early pregnancy; (2) a consequence of immunological responses against the genetically foreign embryo; or (3) due to production of platelet-activating factors by the fertilized ovum.

Blood platelets have a central role in both coagulation and immune reactions (Willis, 1978) and thrombocytopenia most commonly accompanies conditions such as immunological reactions and intravascular coagulation. Platelet activation and thrombocytopenia have been implicated in graft rejection (Lowenhaupt \& Nathan, 1969), reaction to bacteria and viruses (Copley, 1978), the Shwartzman reaction (reaction to bacterial endotoxin) (McKay, Shapiro \& Shanberge, 1965), and the Arthus reaction (generalized or local anaphylactic reaction) (Butler \& White, 1975).

Matings of histoincompatible parents result in zygotes which can be considered allografts and the preimplantation mouse embryo has been shown to express paternal $\mathrm{H}-2$ and non- $\mathrm{H}-2$ antigens,

* Present address: IVF laboratory, Department of Obstetrics and Gynaecology, University of Sydney, Royal North Shore Hospital, St Leonards, New South Wales 2065 , Australia. 
albeit at low levels (Muggleton-Harris \& Johnson, 1976; Heyner, Hunziker \& Zink, 1980; Epstein, Smith \& Travis, 1980; Savicki, Magnuson \& Epstein, 1981).

The role of blood platelets as mediators and promoters of blood coagulation is well defined (Holmsen, Salganicoff \& Fukami, 1977). In vivo, platelet activation may either initiate, or be caused by, the coagulation cascade. The end result in both cases is the consumption of platelets.

To determine whether platelet-activating factors are produced by the zygote the effect of embryo culture medium upon the peripheral blood platelet count of splenectomized mice was determined and compared with the effects of activators of the three main pathways of platelet activation (Haslam, 1964).

\section{Materials and Methods}

Female mice of the Quackenbush, CBA/J or C57BL/6 strains were exposed to light from $07: 30 \mathrm{~h}$ to $21: 30 \mathrm{~h}$ daily. Females at 10 weeks of age were placed with fertile or vasectomized males and checked each morning for the presence of vaginal plugs (Day 1).

Mice were bled from the periorbital plexus under light ether anaesthesia and platelet counts were performed as described by O'Neill (1985). Briefly, $200 \mu \mathrm{l}$ blood were mixed with EDTA anticoagulant and $10 \mu \mathrm{l}$ of this blood were diluted $1: 200$ with $1 \%(\mathrm{w} / \mathrm{v})$ ammonium oxalate. The platelets were counted using a Neubauer haemocytometer and phase-contrast microscopy.

\section{Experiment 1: effect of genotype}

Syngeneic and allogeneic matings. Syngeneic and allogeneic matings and reciprocal crosses were obtained using mice of the CBA/J and C57BL/ 6 strains. CBA/J mice have the $k$ allele and $\mathrm{C} 57 \mathrm{BL} / 6$ mice the $b$ allele at the H-2 locus. They also differ at other major and minor histocompatibility loci (Staats, 1972). Females aged 10 weeks were mated with 3-6-month-old-males.

Females were removed on the day that a vaginal plug was observed. Platelet counts were performed before mating and at 16:00 $\mathrm{h}$ on Day 2 of pregnancy.

Parthenogenesis. Females of the Quackenbush strain, 10 weeks of age, were induced to ovulate by an injection of 5 i.u. PMSG (Folligon: Intervet, Boxmeer, The Netherlands) and 5 i.u. hCG (Chorulon: Intervet). After $12 \mathrm{~h}$, parthenogenesis was induced by anaesthetizing animals with 2,2,2-tribromoethanol (Fluka AG, Switzerland), freshly prepared as a $1 \cdot 2 \%(\mathrm{w} / \mathrm{v})$ solution in $0 \cdot 154$ $\mathrm{M}-\mathrm{NaCl}$ and given at a dose of $0.02 \mathrm{ml} / \mathrm{g}$ body weight (Kaufman, 1978). Such treatment has been shown to induce parthenogenetic activation of ova in about $20 \%$ of treated females (Kaufman, 1978).

Animals were autopsied $24 \mathrm{~h}$ later to determine whether parthenogenesis had occurred. The oviducts were flushed with Dulbecco's phosphate buffered saline (PBS) (pH 7.4) (8.0 g NaCl, $0.2 \mathrm{~g}$ $\left.\mathrm{KCl}, 1 \cdot 15 \mathrm{~g} \mathrm{Na}_{2} \mathrm{HPO}_{4}, 0.2 \mathrm{~g} \mathrm{KH}_{2} \mathrm{PO}_{4}, 0 \cdot 1 \mathrm{~g} \mathrm{CaCl}_{2}, 0.1 \mathrm{~g} \mathrm{MgCl}_{2} .6 \mathrm{H}_{2} \mathrm{O} / \mathrm{l}\right)$.

The presence of 2-cell embryos indicated successful parthenogenetic activation.

Blood was collected and platelet counts performed before the administration of gonadotrophins and immediately before autopsy. As a further control, platelets were counted from animals injected with gonadotrophins but not anaesthetic.

\section{Experiment 2: activation of the coagulation cascade}

All mice used in these experiments were 10-week-old Quackenbush females that had been mated with intact or vasectomized males to give pregnant and pseudopregnant mice, respectively, and they were bled between 10:00 and 11:00 h on Day 2 .

Blood was collected into sodium citrate anticoagulant $(3 \cdot 2 \%(\mathrm{w} / \mathrm{v}), 1$ part to 9 parts of blood), mixed and immediately placed on ice. Each mouse was subsequently autopsied and the 
reproductive tract flushed to obtain embryos for confirmation of pregnancy or pseudopregnancy. The blood from 3 mice was pooled in siliconized glass tubes. All assays were performed in duplicate on the pooled blood and 5 pooled samples were assayed for each treatment, unless otherwise indicated.

Platelet-rich plasma. Whole blood was centrifuged at $300 \mathrm{~g}$ for $10 \mathrm{~min}$ at $4^{\circ} \mathrm{C}$. This treatment caused sedimentation of erythrocytes but not platelets. Platelet-rich plasma was aspirated into a siliconized Pasteur pipette and placed into siliconized glass tubes $(13 \times 75 \mathrm{~mm}) \mathrm{kept}$ at $4^{\circ} \mathrm{C}$ until assay.

Platelet-poor plasma. Blood was centrifuged at $200 \mathrm{~g}$ for $10 \mathrm{~min}$ at $4^{\circ} \mathrm{C}$. The platelet-poor plasma was aspirated and placed into siliconized glass tubes.

Bleeding time. Mice were placed in restraining cages with their tail exposed. The tail was placed in $0.154 \mathrm{M}-\mathrm{NaCl}$ maintained at $37^{\circ} \mathrm{C}$. After a 5 -min equilibration period the tail was cut, with sharp scissors, $10 \mathrm{~mm}$ from its tip and then placed back into the saline solution. The time that the wound continued to bleed was recorded.

Clotting time. Whole blood $(100 \mu \mathrm{l})$ was placed in a $13 \times 75 \mathrm{~mm}$ siliconized glass test tube and placed in a $37^{\circ} \mathrm{C}$ water bath for $2 \mathrm{~min}$. Prewarmed $25 \mathrm{~mm}$-calcium chloride $(100 \mu \mathrm{l})$ was added to the blood and a stopwatch started simultaneously. The tube was placed within a larger test tube containing water at $37^{\circ} \mathrm{C}$. The tube was gently rocked and the time taken for clot formation recorded.

The same procedure was carried out using platelet-rich plasma and platelet-poor plasma from pregnant and pseudopregnant mice. The platelet-rich plasma was standardized to a concentration of $10^{6}$ platelets $/ \mu \mathrm{l}$.

Platelet factor III. Platelet-rich plasma was collected and the platelet concentration adjusted to $10^{6} / \mu \mathrm{l}: 100$ samples were incubated with $100 \mu \mathrm{l}$ imidazole-buffered saline ( $\mathrm{pH} \mathrm{7.4)} \mathrm{containing} 5 \mathrm{mg}$ $\mathrm{kaolin} / \mathrm{ml}$ (Ajax Chemicals, Sydney, Australia). The samples were incubated at $37^{\circ} \mathrm{C}$ for $0,20,40$ and $60 \mathrm{~min}$. The extent of kaolin-induced release of platelet factor III was tested by measuring the clotting time after recalcification (Roper-Drewinko et al., 1981).

Activated partial thromboplastin time. The intrinsic clotting pathway was studied by mixing $100 \mu l$ platelet-poor plasma with $100 \mu \mathrm{l}$ reconstituted rabbit brain extract (partial thromboplastin) and the solid activator, celite (Cephalite: bioMerieux, Charbonierres Les Bains, France). This was incubated at $37^{\circ} \mathrm{C}$ for exactly $3 \mathrm{~min}$. Prewarmed calcium chloride (100 $\left.\mu \mathrm{l}, 25 \mathrm{~mm}\right)$ was added, and the clotting time recorded (Proctor \& Rapaport, 1961).

Prothrombin (complete thromboplastin) time. The extrinsic coagulation pathway was examined by adding $100 \mu \mathrm{l}$ prewarmed, complete thromboplastin containing excess calcium (thromboplastin with calcium; bioMerieux, France) to $100 \mu \mathrm{l}$ prewarmed platelet-poor plasma. The thromboplastin was used as $1: 2,1: 4$ and $1: 8$ dilutions in Michaelis buffer (bioMerieux, France), and the clotting time was recorded (Quick, 1935).

Statistical analysis. Student's $t$ test was used to compare the means of the bleeding and clotting times from pregnant and pseudopregnant mice. An analysis of variance was used for the platelet factor III generation and prothrombin time results. The Newman-Keuls test was used for comparisons of the means.

\section{Experiment 3}

The ability of mouse embryos to produce platelet-activating factors was tested by examining the effects of embryo culture medium on the peripheral blood platelet count of mice.

Testing of culture medium. Medium was given as a single intraperitoneal (i.p.) injection into a splenectomized mouse. Various doses were given to produce a dose-response curve and mice were bled and platelet counts performed immediately before and $30 \mathrm{~min}$ after injection. In a subsequent experiment the dose was standardized to $200 \mu$ l and animals were bled 5, 10, 20, 40,60 and 120 min after injection. 
Sufficient culture medium was pooled to complete each series of experiments. The culture medium was thawed once only. Each treatment was performed in triplicate, unless indicated otherwise. The results are expressed as the percentage change in platelet count compared to the count before injection.

Splenectomy. Female Quackenbush mice, 8-10 weeks old, and weighing about $35 \mathrm{~g}$, were anaesthetized and the spleen removed through a left para-medial dorsal incision. The major blood vessels were clamped with small haemostats. The spleen was excised; after 2-3 min the haemostats were removed and the splenic fat pad was replaced. Animals were left to recover for 7 days before any further treatments.

Embryo culture. Embryos at the 8-16-cell stage, or unfertilized eggs, were collected from the oviduct of Day-2 pregnant or pseudopregnant mice. All morphologically normal embryos were pooled and groups of 30 were placed in $200 \mu$ l of Medium W1 containing $3 \mathrm{mg} \mathrm{BSA} / \mathrm{ml}$ (O'Neill \& Quinn, 1981) in disposable Petri dishes (Sterilin Ltd, Teddington, Middlesex, U.K.) under paraffin oil (BDH, Sydney, Australia).

Testing known platelet activators. Activators of the three primary pathways of platelet activation (Haslam, 1964) were tested to determine whether they displayed a profile of activation in vivo similar to that caused by embryo culture medium.

Adenosine- 5 -diphosphate (sodium salt . $2 \mathrm{H}_{2} \mathrm{O}$ : Calbiochem-Behring, Aust. Pty Ltd, Sydney, Australia) was prepared at a concentration of $5 \mathrm{mg} / \mathrm{ml}$ in PBS and, after dilution, doses of $1 \cdot 0,0 \cdot 25$ or $0.06 \mathrm{mg}$ in $200 \mu \mathrm{l}$ PBS were injected into splenectomized mice. Arachidonic acid (porcine liver: Calbiochem-Behring) was dissolved in chloroform and then made up in PBS. Splenectomized mice were given doses of $0.5,0.1$ or $0.05 \mathrm{mg}$ in $200 \mu \mathrm{l}$. Synthetic platelet-activating factor (PAF-acether) (Calbiochem-Behring), $1 \mathrm{mg}$, was resuspended in $1 \mathrm{ml}$ chloroform-methanol $(2: 1 \mathrm{v} / \mathrm{v})$ and was then diluted in PBS containing $0.25 \%$ bovine serum albumin (PBS-BSA). Various volumes of this preparation were tested in the bioassay.

\section{Results}

\section{Experiment 1}

Significant thrombocytopenia resulted from the syngeneic and allogeneic matings (Table 1). The extent of thrombocytopenia was similar in all crosses performed.

The blood platelet count (mean \pm s.e.m.) after parthenogenetic activation of ova (1086 $\pm 84 \times$ $10^{3} / \mu 1,5$ replicates) was significantly lower $(P<0.01)$ than in those mice given gonadotrophins without anaesthesia $\left(1695 \pm 154 \times 10^{3} / \mu \mathrm{l}, 4\right.$ replicates $)$, and in those in which parthenogenesis did not occur after administration of tribromoethanol $\left(1612 \pm 125 \times 10^{3} / \mu 1,7\right.$ replicates $)$.

Table 1. The peripheral blood platelet count of two inbred strains of mice before mating and on Day 2 of pregnancy after syngeneic and allogeneic mating

\begin{tabular}{llllc}
\hline \multicolumn{2}{c}{ Cross } & & \multicolumn{2}{c}{ Platelet count $\left(10^{-3} / \mu \mathrm{l}\right)$} \\
\cline { 5 - 5 } Male & Female & & Before mating & Day 2 \\
\hline CBA & CBA & & $1209 \pm 53$ & $1017 \pm 51^{* *}$ \\
CBA & C57BL & & $1317 \pm 130$ & $983 \pm 115^{* *}$ \\
C57BL & CBA & & $1150 \pm 131$ & $876 \pm 105^{*}$ \\
C57BL & C57BL & & $1330 \pm 91$ & $940 \pm 124^{* * *}$ \\
\hline
\end{tabular}

Values are mean \pm s.e.m. for 5 mice.

$* P<0.05,{ }^{* *} P<0.01,{ }^{* * *} P<0.005$ (ANOV). 


\section{Experiment 2}

There was no difference $(P>0.05)$ in (1) the bleeding time and (2) the clotting time of whole blood from Day-2 pregnant and pseudopregnant mice (Table 2). After standardization of platelet concentration to $10^{6} / \mu \mathrm{l}$, a significant reduction $(P<0.005)$ in the clotting time of platelet-rich plasma occurred in pregnant compared with pseudopregnant mice. The clotting time of plateletpoor plasma from pregnant mice was also less $(P<0.05)$ than that from pseudopregnant mice (Table 2).

Table 2. Bleeding and clotting time (sec) on Day 2 of pregnancy and pseudopregnancy

\begin{tabular}{lcc}
\hline & Pregnant mice & Pseudopregnant mice \\
\hline Bleeding time & $65 \pm 4 \cdot 3$ & $56 \pm 10.7$ \\
Clotting time & $65 \pm 7 \cdot 5$ & $67 \pm 5 \cdot 4$ \\
Whole blood & $50 \pm 2 \cdot 05^{* * *}$ & $64 \pm 4 \cdot 1$ \\
Platelet-rich plasma & $68 \pm 1 \cdot 2^{*}$ & $74 \pm 1.6$ \\
Platelet-poor plasma & $22 \cdot 2 \pm 0.8$ & $20.9 \pm 1.5$ \\
Activated partial thromboplastin time & 22.8 \\
\hline
\end{tabular}

Values are mean \pm s.e.m. of 5 blood samples.

$* P<0.05, * * P<0.005$ compared with value in pseudopregnant mice (Student's $t$ test).

Despite this shortening of the clotting time of plasma from pregnant mice, there was no difference in the activity of the extrinsic (Text-fig. 1) or intrinsic (Table 2) pathways of the coagulation cascade. Examination of the ability of platelets to produce a thromboplastin, platelet factor III, showed that platelets from pregnant mice released factor III significantly faster $(P<$ 0.001 ) than did platelets from pseudopregnant mice (Text-fig. 2). This result showed that changes in the blood coagulation system during pregnancy were due to the increased release of platelet factor III.

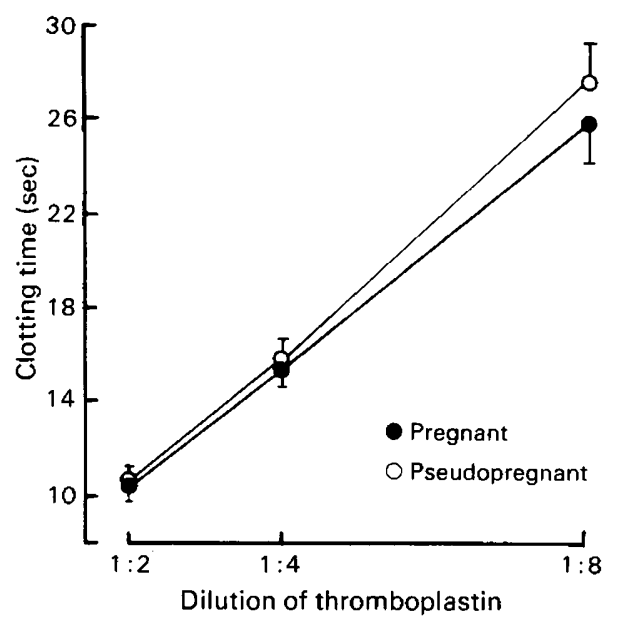

Text-fig. 1. The activity of the extrinsic pathway of blood coagulation of Day-2 pregnant and pseudopregnant mice was assessed by the prothrombin time. The clotting time of plasma was measured at various doses of thromboplastin. Each point is the mean \pm s.e.m. of 5 samples. 


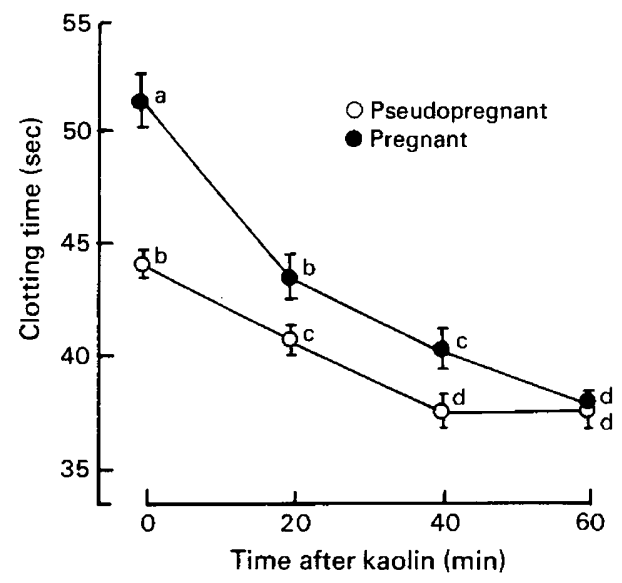

Text-fig. 2. The release of platelet factor III by platelet-rich plasma on Day 2 of pregnancy and pseudopregnancy in mice. Each point represents the mean \pm s.e.m. of 5 animals. Points with different letters are significantly different $(P<0.05)$, based on the Newman-Keuls multiple comparisons test.

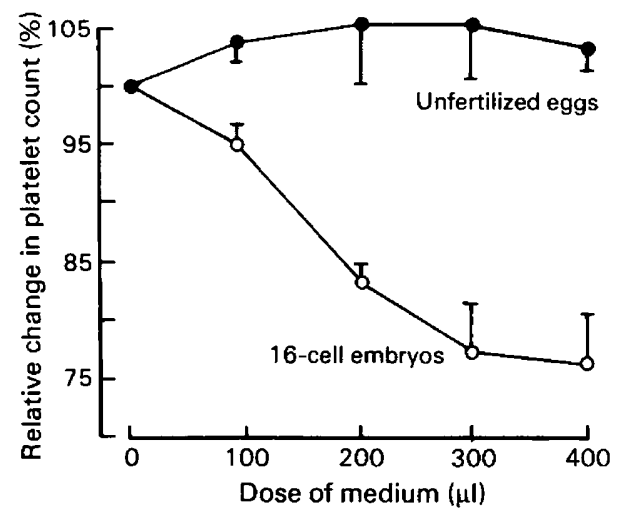

Text-fig. 3. Changes to the platelet count of splenectomized mice after injection of various doses of embryo culture medium in which 16-cell embryos were grown for $24 \mathrm{~h}$ or unfertilized eggs were cultured for the same period. Each point is the mean \pm s.e.m. for 3 different culture media.

\section{Experiment 3}

Culture media in which 8-16-cell embryos grew for $24 \mathrm{~h}$ contained factor(s) which caused significant thrombocytopenia in splenectomized mice. This effect was dose-dependent, showing a maximum response after injection of at least $300 \mu \mathrm{l}$ culture medium (Text-fig. 3). The reaction occurred within $5 \mathrm{~min}$ and reached a maximum at $10 \mathrm{~min}$, persisting for up to $120 \mathrm{~min}$ (Text-fig. 4). There was no reduction in platelet concentration after injection of media from cultures of unfertilized ova. The elevation in platelet numbers in control animals was probably due to the reduction in plasma volume that was observed after injection (Text-fig. 4). This change in haematocrit occurred after injection of control and embryo culture media. These changes in plasma volume were not taken into account when calculating the change in platelet count. 


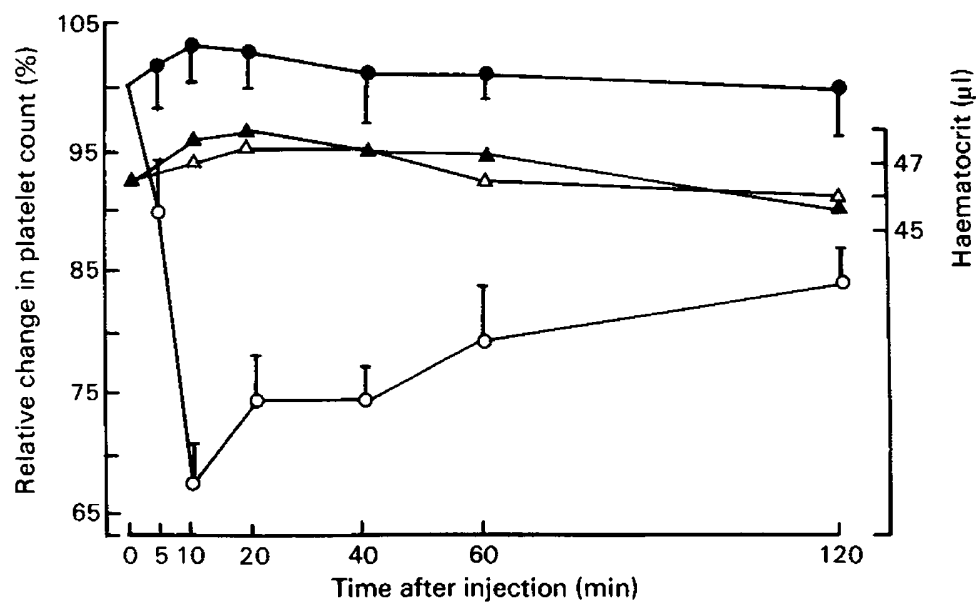

Text-fig. 4. Changes to the platelet count $(O)$ and haematocrit $(\triangle)$ at various times after injection of embryo culture medium $(O, \triangle)$ and control medium $(O, \Delta)$ into splenectomized mice. The results are mean \pm s.e.m. for 3 different media.

In a study of 15 different embryo culture media, 12 displayed the ability to induce thrombocytopenia while $3 \mathrm{did}$ not show any activity. This occurred despite the fact that the embryos in all cultures appeared morphologically normal (results not shown).

Using the splenectomized mouse bioassay, neither adenosine diphosphate nor arachidonic acid had platelet-activating effects at any dose tested. Intraperitoneal injection of small doses of 1-0alkyl-2-acetyl-sn-glycero(3)phosphocholine caused a significant thrombocytopenia in splenectomized mice (Text-fig. 5). It also showed a parallel dose-response curve and the same temporal profile of onset of thrombocytopenia to that induced by embryo culture medium (Text-fig. 6).

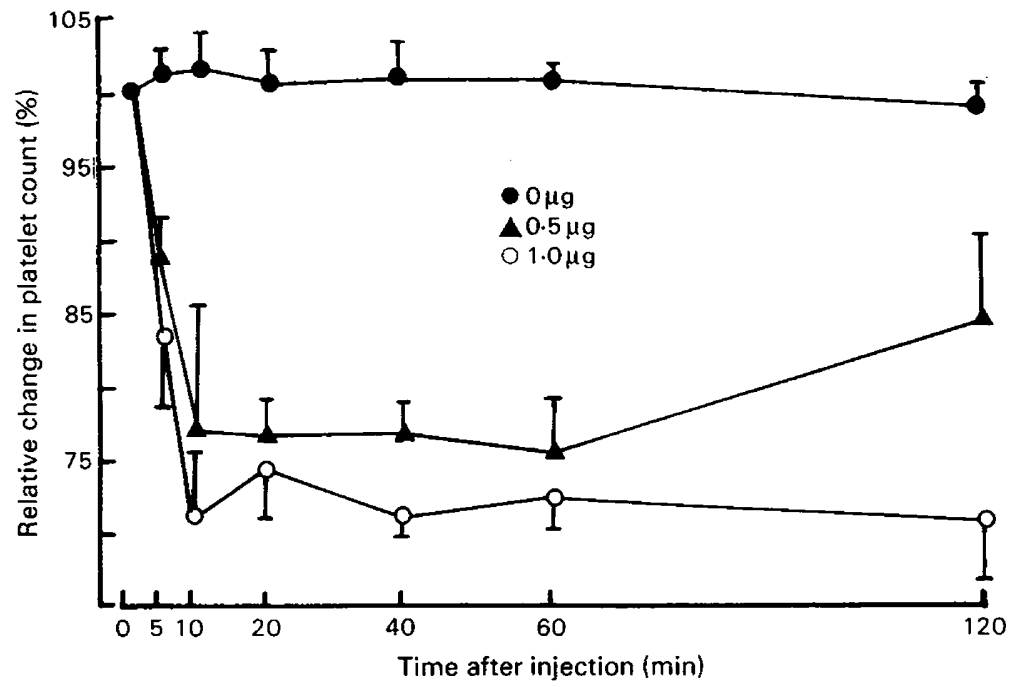

Text-fig. 5. The change in platelet count of splenectomized mice after injection of PAF-acether. The results are mean \pm s.e.m. for 3 mice. 


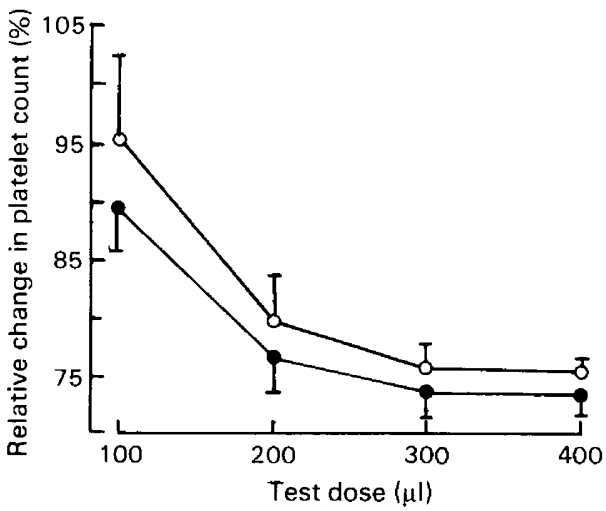

Text-fig. 6. The change in the platelet count of splenectomized mice after injection of various doses of embryo culture medium $(O)$ and PAF-acether $(2.5 \mu \mathrm{g} / \mathrm{ml})(\odot)$. The results are mean \pm s.e.m. of 4 mice.

\section{Discussion}

Syngeneic mating produces embryos which are homologous at all loci on the autosomal chromosomes. However, there was a similar significant reduction in the platelet count after both syngeneic and allogeneic matings (Table 1) suggesting that early pregnancy-associated thrombocytopenia was not due to immunological recognition of the genetically foreign embryo.

Preimplantation mouse embryos express the $\mathrm{H}-\mathrm{Y}$ antigen when fertilized by spermatozoa carrying the Y chromosome (Krco \& Goldberg, 1976; Epstein et al., 1980). Thus, even in sygeneic matings, these embryos could provide an immunological target. To overcome this objection, the platelet count was performed on females with parthenogenetically activated ova. Such embryos develop normally throughout the preimplantation stage of pregnancy, but do not provide immunological targets. Despite this, significant thrombocytopenia occurred $24 \mathrm{~h}$ after parthenogenetic activation of ova. This was not due to an effect on the platelet count by the gonadotrophins or the anaesthetic.

It is possible that there may be immunological recognition of embryo-specific antigens expressed by the preimplantation embryo (Shevinsky, Knowles, Damjanov \& Solter, 1982) but a direct test is difficult. However, the very rapid onset of thrombocytopenia (O'Neill, 1985) and the demonstration of production of platelet-activating factor(s) by the embryo suggests that this is unlikely to be the case.

The reduction in platelet count after mating of inbred strains of mice was not as great as in Quackenbush strain mice. The reason for this diminished response is probably due to the fact that CBA/J and C57BL/6 mice produced fewer embryos (7.7 and 7.2 implantation sites, respectively (Harlow, 1980)) than did Quackenbush strain mice (14.4 implantation sites, results not shown). O'Neill (1985) showed that the degree of thrombocytopenia was correlated with the number of embryos present in the reproductive tract.

Platelets are activated by a vast range of factors (review by Holmsen et al., 1977). Physiologically, the most important of these are factors produced by the fluid phase of the blood coagulation cascade, e.g. thrombin. Intravascular activation of the coagulation cascade causes platelet activation and consumption. The results do not provide support for the role of the fluid phase of the blood coagulation cascade in the induction of early pregnancy-associated thrombocytopenia (Table 2; Text-fig. 1). Bleeding and clotting times are dependent upon the platelet concentration and the concentration and activity of the factors of the coagulation cascade 
(Harker \& Slichter, 1972). Since there was a reduction in the platelet concentration during early pregnancy (O'Neill, 1985) an increase in the bleeding and clotting times were similar for pregnant and pseudopregnant mice (Table 2). The activity of the intrinsic (Table 2) and extrinsic (Text-fig. 1) pathways of coagulation did not increase during early pregnancy and could not, therefore, explain the maintenance of normal bleeding times in the presence of thrombocytopenia.

When the platelet concentration of plasma from pregnant and pseudopregnant mice was standardized to $10^{6} / \mu \mathrm{l}$, a reduction occurred in clotting time of blood from pregnant mice (Table 2). Platelets exert a major effect on blood clotting by the release of platelet factor III. The release of this factor was enhanced on Day 2 of pregnancy (Text-fig. 2). This increased availability of platelet factor III during early pregnancy explains why normal bleeding times were maintained even when the platelet concentration was reduced. Increased platelet factor III activity was also likely to be the reason for the reduced clotting time of platelet-poor plasma from Day-2 pregnant mice (Table 2). Platelet factor III is released after activation of platelets. If the thrombocytopenia associated with early pregnancy was simply due to platelet destruction, for instance by the reticuloendothelial system, then platelet factor III activity would not occur (Hardisty \& Hutton, 1966; Mustard, Glynn, Nishizawa \& Packham, 1967). The fact that its activity was elevated provides evidence that thrombocytopenia was due to platelet activation and consumption in vivo. This increased platelet activation was shown to be caused by the production of soluble factor(s) by preimplantation mouse embryos. This factor(s) caused a dose-dependent reduction in platelet count in splenectomized mice and the onset of thrombocytopenia was very rapid (Text-fig. 4). Medium in which unfertilized eggs had been cultured showed no activity, indicating that the production of the platelet-activating activity was embryo dependent.

The use of a splenectomized mouse bioassay for the detection of platelet-activating factors is a novel method. It provides a rapid, simple and inexpensive approach to what can be a technically demanding task. The use of splenectomized mice serves to increase the sensitivity of the bioassay. The spleen acts as a reservoir of platelets and treatments which cause vascular consumption of platelets result in splenic contraction and expulsion of platelets (O'Neill, 1985). The removal of this reservoir means that any change in the total platelet population is reflected as a change in the peripheral blood platelet count. The ADP and arachidonic acid pathways of platelet activation had little effect in this assay while PAF-acether had very potent platelet-activating effects (Text-fig. 5). The failure of ADP and arachidonic acid to cause thrombocytopenia was probably due to degradation of these reagents before they could have significant effects on platelets in circulation. Intravenous administration of these promoters may have resulted in more profound effects. This experiment was not necessary, however, since the active factor in embryo culture medium exerted its effects after intraperitoneal injection. PAF-acether had a temporal profile of induction of thrombocytopenia that was similar to and a dose-response curve that was parallel to that caused by embryo culture medium (Text-figs $5 \& 6$ ). This suggests that the active factor(s) may have been the same or were exerting their effects via the same pathway as PAF-acether.

Fishel \& Surani (1980) described the production of a high molecular weight glycoprotein by the preimplantation mouse embryo but a biological function for this factor was not described. Cavanagh, Morton, Rolfe \& Gidley-Baird (1980) described a low molecular weight factor produced by the zygote which acted in concert with factors from the oviduct and ovary to exert, as yet, illdefined effects on maternal lymphocytes. There have been no previous reports of the production by the preimplantation mammalian embryo of factor(s) with the potent physiological effects described here. It will be important to characterize biochemically the factor produced by embryos to determine whether it is homologous to the platelet-activating factor, 1-0-alkyl-2-acetyl-snglycero(3)phosphocholine. PAF-acether was first discovered by the observation that leucocytes, sensitized with specific IgE antibody and challenged with antigen in vitro, released a potent substance which caused platelet activation (Benveniste, Henson \& Cochrane, 1972). It was produced by basophils (Benveniste, 1974), neutrophils (Lotner, Lynch, Betz \& Henson, 1980), macrophages (Ninio, Mencia-Huerta, Heymans \& Benveniste, 1982), monocytes (Camussi, Tetta, 
Segoloni, Deregibus \& Bussolino, 1981), platelets (Chignard, Le Couedic, Tence, Vargaftig \& Benveniste, 1979) and the renal medulla (Blank, Snyder, Byers, Brooks \& Muirhead, 1979). The wide diversity of cell types which produce PAF-acether, its relatively simple biosynthetic pathway (Polonsky et al., 1980; Ninio et al., 1982) and its potency at low concentrations (Camussi, Tetta \& Bussolino, 1983) make it an attractive candidate for an early embryonic message.

The effect of platelet activation and thrombocytopenia induced by embryo-derived factors on the outcome of pregnancy is yet to be defined. The discovery of an embryo-derived platelet activating factor and its detection by a simple bioassay suggests that it may be possible to use this factor: (1) as a quantifiable and non-invasive means of assessing the viability of embryos in vitro; (2) as a method of quality control of embryo culture procedures; and (3) to allow the survival of embryos to be monitored in utero.

\section{This work was supported in part by the Australian Research Grants Scheme.}

\section{References}

Benveniste, J. (1974) Platelet-activating factor, a new mediator of anaphylaxis and immune complex deposition from rabbit and human basophils. Nature, Lond. 249, 581-882.

Benveniste, J., Henson, P.M. \& Cochrane, C.G. (1972) Leukocyte-dependent histamine release from rabbit platelets. The role of $\mathrm{IgE}$, basophils and a plateletactivating factor. J. exp. Med. 136, 1356-64.

Blank, M.L., Snyder, G., Byers, I.W., Brooks, G. \& Muirhead, E.E. (1979) Antihypertensive activity of an alkyl ether analog of phosphatidylcholine. Biochem. Biophys. Res. Commun. 90, 1194-1200.

Butler, K.D. \& White, A.M. (1975) The effect of sulphinpyrazone on the thrombocytopenia occurring in the Arthus reaction. Br. J. Pharmac. 55, 256-257.

Camussi, G., Tetta, C., Segoloni, G., Deregibus, M.C. \& Bussolino, F. (1981) Neutropenia induced by plateletactivating factor (PAF-acether) released from neutrophils: the inhibitory effect of prostacyclin $\left(\mathrm{PGI}_{2}\right)$. Agents and Actions 11, 550-556.

Camussi, G., Tetta, C. \& Bussolino, F. (1983) Inhibitory effect of prostacyclin $\left(\mathrm{PGI}_{2}\right)$ on neutropenia induced by intravenous injection of platelet-activating factor (PAF) in the rabbit. Prostaglandins 25, 343-351.

Cavanagh, A.C., Morton, H., Rolfe, B.E. \& Gidley-Baird, A.A. (1980) Ovum factor: a first signal of pregnancy. Proc. 4th Int. Congr. Immunol., Paris, Abstr. 16.4.05.

Chignard, M., Le Couedic, J.P., Tence, M., Vargaftig, B.B. \& Benveniste, J. (1979) The role of platelet activation factor in platelet aggregation. Nature, Lond. 279, 799-800.

Copley, A.L. (1978) Platelets and physiological defence mechanisms. In Platelets: A Multidisciplinary Approach, pp. 161-167. Eds G. de Gaetano \& S. Garattini. Raven Press, New York.

Epstein, C.J., Smith, S. \& Travis, B. (1980) Expression of $\mathrm{H}-\mathrm{Y}$ antigen on preimplantation mouse embryos. Tissue Antigens 15, 63-67.

Fishel, S.B. \& Surani, M.A.H. (1980) Evidence for synthesis and release of a glycoprotein by mouse blastocysts. $J$. Reprod. Fert. 59, 181-185.

Hardisty, R.M. \& Hutton, R.A. (1966) Platelet aggregation and availability of platelet factor III. Br. J. Haematol. 12, 764-776.
Harker, L.A. \& Slichter, S. (1972) The bleeding time as a screening test for evaluation of platelet functions. $N$. Engl. J. Med. 287, 155-156.

Harlow, G.M. (1980) Some studies of the development and differentiation of the early mouse embryo. Ph.D. thesis, University of Newcastle, Australia.

Haslam, G.M. (1964) Role of adenosine diphosphate in the aggregation of human blood-platelets by thrombin and by fatty acid. Nature, Lond. 202, 765768 .

Heyner, S., Hunziker, R.D. \& Zink, G.L. (1980) Differential expression of minor histocompatibility antigens on the surface of the mouse oocyte and preimplantation developmental stages. $J$. Reprod. Immunol. 2, 269-279.

Holmsen, H., Salganicofi, L. \& Fukami, M.H. (1977) Platelet behaviour and biochemistry. In Haemostasis: Biochemistry, Physiology and Pathology, pp. 239319. Eds D. Ogston \& B. Bennett. John Wiley, London.

Kaufman, M.T. (1978) The experimental production of mammalian parthenogenetic embryos. In Methods in Mammalian Reproduction, pp. 21-47. Ed. J. C. Daniel, Jr. Academic Press, New York.

Krco, C.J. \& Goldberg, E.H. (1976) H-Y (male) antigen: detection on 8-cell embryos. Science, N.Y. 193, 11341135.

Lotner, G.Z., Lynch, J.M., Betz, S.J. \& Henson, P.M. (1980) Human neutrophil-derived platelet activating factor. J. Immunol. 124, 666-684.

Lowenhaupt, R. \& Nathan, P. (1969) The participation of platelets in the rejection of dog kidney allotransplants: hematologic and electron microscopic studies. Transplant. Proc. 1, 305-310.

McKay, D.G., Shapiro, S.S. \& Shanberge, J.N. (1965) Alterations in the blood coagulation system induced by bacterial endotoxins. II. In vitro. J. exp. Med. 107, 369-376.

Muggleton-Harris, A.L. \& Johnson, M.H. (1976) The nature and distribution of serologically detectable alloantigens on the preimplantation mouse embryo. J. Embryol. exp. Morph. 35, 59-72.

Mustard, J.F., Glynn, M.F., Nishizawa, E.E. \& Packham, M.A. (1967) Platelet surface interactions; relation- 
ship to thrombosis and haemostasis. Fedn Proc. Fedn Am. Socs exp. Biol. 20, 106-114.

Ninio, E., Mencia-Huerta, J.M., Heymans, F. \& Benveniste, J. (1982) Biosynthesis of platelet-activating factor. I. Evidence for an acetyl transferase activity in murine macrophages. Biochim. Biophys. Acta 710, 23-31.

O'Neill, C. (1985) Thrombocytopenia is an initial maternal response to fertilization. J. Reprod. Fert. $\mathbf{7 3}$, (in press).

O'Nell, C. \& Quinn, P. (1981) Interaction of uterine flushings with mouse blastocysts in vitro as assessed by the incorporation of $\left[{ }^{3} \mathrm{H}\right]$ uridine. $J$. Reprod. Fert. 62, 257-62.

Polonsky, J., Tence, M., Varenne, P., Das, B.C., Lunel, J. \& Benveniste, J. (1980) Release of 1-0-alkylglyceryl-3phosphorylcholine, 0 -deacetyl platelet-activating factor, from leucocytes: chemical ionization mass spectrometry of platelets. Proc. natn. Acad. Sci. U.S.A. 77, 7019-7023.

Proctor, P.R. \& Rapaport, S.I. (1961) The partial thromboplastin time with kaolin. Am. J. clin. Path. 36, 312-318.
Quick, A.J. (1935) Determination of prothrombin time. Am. J. med. Sci. 190, 501-509.

Roper-Drewinko, P.R., Drewinko, B., Corrigan, G., Johnston, D., MeCredie, K.B. \& Freireich, E.J. (1981) Standardization of platelet function tests. Am. J. Hematol. 11, 183-203.

Savicki, J., Magnuson, J. \& Epstein, C.J. (1981) Evidence for expression of the paternal genome in the two-cell mouse embryo. Nature, Lond. 294, 450-451.

Shevinsky, L.M., Knowles, B.B., Damianov, L. \& Solter, D. (1982) Monoclonal antibody to murine embryos defines a stage-specific embryonic antigen expressed on mouse embryos and human teratocarcinoma cells. Cell 30, 697-705.

Staats, J. (1972) Standardized nomenclature for inbred strains of mice. Cancer Res. 32, 1609-1646.

Willis, A.L. (1978) Platelet aggregation mechanisms and their implications in haemostasis and inflammatory disease. In Handbook of Experimental Pharmacology, 50/1, Inflammation, pp. 138-205. Eds J. R. Vane \& S. H. Ferreira. Springer-Verlag, Berlin.

Received 12 July 1984 